\title{
Basis for a Functional Capacity Evaluation Methodology for Patients with Work-related Neck Disorders
}

\author{
David D. Reesink · Wim Jorritsma $\cdot$ Michiel F. Reneman
}

Received: 7 February 2007 / Accepted: 30 April 2007/Published online: 22 May 2007

(C) Springer Science+Business Media, LLC 2007

\begin{abstract}
Background Neck pain is a common musculoskeletal complaint and a relationship with reduced work-related functional capacity is assumed. A validated instrument to test functional capacity of patients with neck pain is unavailable. The objective of this study was to develop a Functional Capacity Evaluation (FCE), which is content valid for determining functional capacity in patients with work related neck disorders (WRND). Methods A review of epidemiological review literature was conducted to identify physical risk factors for WRND.

Results Evidence was found that physical risk factors contribute in development of WRND. Physical risk factors were related to repetitive movements, forceful movements, awkward positions and static contractions of the neck or the neck/shoulder region. An FCE was designed based on the risk factors identified. Eight tests were selected to cover all risk factors: repetitive side reaching, repetitive reaching overhead, static overhead work, front carry, forward static bend neck, overhead lift and the neck strength test. Content validity of this FCE was established by providing the rationale, specific objectives and operational definitions of the FCE.

Conclusions Further research is needed to establish reliability and other aspects of validity of the neck-FCE.
\end{abstract}

D. D. Reesink $(\square)$

University Center ProMotion Groningen, P. O. Box 247, 9700 AE Groningen, The Netherlands e-mail: info@ucpromotiongroningen.nl

W. Jorritsma · M. F. Reneman

Center for Rehabilitation, University Medical Center Groningen, University of Groningen,

Groningen, The Netherlands

M. F. Reneman

Center for Work and Health, University Medical Center Groningen, Groningen, The Netherlands

M. F. Reneman

Northern Center for Health Care Research, University Medical Center Groningen, Groningen,

The Netherlands 
Keywords Occupational rehabilitation - Work related neck disorders . Validity $\cdot$ Functional capacity evaluation $\cdot$ Neck pain

\section{Introduction}

Neck pain is a common musculoskeletal complaint [1]. Among the general population in the Netherlands, the 12-month prevalence of neck pain was $31.4 \%$ [2]. Among the general working population in the Netherlands the 12-month prevalence figures for low back, neck and shoulder complaints, were respectively 44.5, 28.5, and $27.3 \%$ [3]. Prevalence in the general population in other countries are similar [4-8]. The 1-year prevalence of neck pain varies among different occupational groups from 6 to $76 \%$, with higher values for female workers [5, 9-13]. The pathological basis for neck pain is unclear in approximately $80 \%$ of the cases [14]; the term "non-specific" is applied to these cases [15]. Neck pain is often concurrent with shoulder pain $[2,16]$. Dysfunction of the cervico-thoracic region strongly predicts development of shoulder complaints [17, 18]. A limited shoulder/arm function, can affect the prevalence of neck pain. Neck pain can be a substantial burden on society, because it is related to work disability, unemployment and insurance claims. The majority of these costs are not related to health care, but are due to sick leave, disability and loss of productivity [19].

Work related neck pain (WRNP) is a multi-factorial disorder among works. It may in part be caused, aggravated, accelerated or exacerbated by occupational exposures, and may be related to impaired work capacity [20]. The definition of WRNP is based on a definition of work related disability by the World Health Organization [21]. In the WHO domain of capacity, the definition of WRNP is characterized by a diminishing work capacity. Work capacity represents the limits of the anatomical, physiological and psychological systems in work-related parameters, which include job demands specific to a job [22]. The work capacity is performance based determined through a functional capacity evaluation (FCE). An FCE aims to measure an individual's physical capability to perform work related activities [23-25]. FCEs are used in work rehabilitation programs, for disability determination, return to work recommendations and in medico-legal issues.

Most research on functional capacity or disability regarding patients with WRND is conducted through questionnaires based on self report. Comparative research between a patient's self report, clinical examination (physician) and FCE has shown little similarity and low correlation in patients with chronic low back pain [26]. Self reported limitations were considerably higher than those derived from clinical examination or from FCE. Limitations based on clinical examinations were higher than those derived from FCE. Each method deals with a different perspective; self-report instruments may reveal a patient's perception of his own performance, clinical examination reveals a physician's perception of a patient's performance and functional testing (FCE) reveals the actual performance of a patient in a standardized assessment setting. Balogh et al. [27] and Hansson et al. [28] have shown that subjects with neck/shoulder complaints rated their work exposure higher than those without, although they in fact showed lower direct measured exposure. 
Thus an FCE specific for patients with neck pain is needed. At this moment, however, no validated performance based instrument has been described in literature.

The objective of this study was to develop an FCE, which is content valid for determining functional capacity in patients with WRND. Content validity is the degree to which test items represent the performance domain the test is intended to measure [29]. To determine content validity it is necessary to establish rational grounds for the test, to provide operational definitions of the test variables and to identify the specific objectives of the test [30]. As previously described in the Journal of Occupational Rehabilitation [31] a review of epidemiological literature was conducted to identify the rational grounds for physical risk factors related to work related upper limb disorders. There is a widely supported idea that there are certain types of work are linked to WRND. Consequently, different work related risk factors should be described. The identified physical risk factors form the basis for a WRND specific FCE. Functional tests will be selected to cover these risk factors.

Besides physical risk factors, also non-physical factors are known to influence WRND and sickness absence [32]. Psychological and personality traits, health beliefs, environmental and social circumstances at work or at home, coping resources, mood, and psychopathology are potentially important in the development or sustenance of WRND [32]. However, this study focuses on physical aspects only, with the objective that this neck-FCE will be content valid in measuring workrelated functional capacity of patients with WRND.

\section{Methods}

\section{Literature review}

The electronic databases MEDLINE (1966-October 2006), EMBASE (1966October 2006) and Cochrane Library (1966-October 2006) were systematically searched to identify work related physical risk factors in epidemiologic review studies. These databases were searched with the following keywords: work related neck disorders, occupational cervicobrachial disorders (and OCD), work related upper extremity disorders (and WRUED), upper extremity musculoskeletal disorders (and UEMS), work-related upper limb disorders (and WRULD), upper limb disorders (and ULD), repetitive strain injury (and RSI), cumulative trauma disorders (and CTD), musculoskeletal disorders (and MSD), and work related cumulative trauma disorders (and WRCTD). These searches were performed in combination with the terms neck or neck/shoulder. Reference lists of the selected studies were screened for additional relevant studies. Relevant review-studies with references to studies already reviewed were excluded to avoid overlap. Full text review articles were included if they identified a work-related risk factor for neck and neck/shoulder pain. Reviews that dealt with neck/shoulder pain were only included if the shoulder was related to neck pain. Only reviews written in English were included. 
Risk factors operational definition and selection

Work related physical risk factors were selected from literature reviews. The content of similar risk factors' were checked for correspondence. To ensure that each similar risk factor definition had the same content, they were operationally defined. The risk factors were operationally defined, with regards to: (1) nature of the risk factor; (2) point within the body being considered [33, 34]; (3) total duration, intensity [33, 34], or frequency of the exposure; and (4) the axis (longitudinal, sagittal, transversal) where the movements or posture of the neck or shoulder was performed. The type of movement or posture defined the nature of a risk factor. Correspondence between risk factors was established if the first three operational definitions showed conformity. When no consensus was reached between the risk factors, they were described separately. A risk factor was excluded when it dealt solely with duration, intensity, or frequency in relation to a specific job. When risk factors were undefined in the reviews, they were suppleted with definitions of other studies dealing with WRND risk factors. Risk factors were included in the FCE when three non-systematic and non-critical reviews, or two systematic and critical reviews, or two systematic reviews concluded that there was a relationship between neck pain and that risk factor.

Test design and selection

An FCE was designed which covered the included physical risk factors as they were operationally defined. Tests were selected based on four criteria:

(1) Whether the test measured at a functional level. When risk factors could not be covered by tests at a functional level, tests measuring at a non-functional level were selected.

(2) Tests were selected when they covered one risk factor. When not available, tests were selected to cover two or more risk factors simultaneously.

(3) If the risk factor was defined on multiple axes, tests were selected to cover these. When not available, tests measuring one axis were selected.

(4) Guidelines in hierarchical order for functional capacity evaluation presented by Hart et al. [35];

(a) Safe: Given the known characteristics of the evaluee, the procedure should not be expected to lead to injury,

(b) Reliability: the test score should be dependable across evaluators, evacuee's, and the date or time of test administration,

(c) Validity: The interpretation of the test score should be able to predict or reflect the evacuee's performance in target work setting,

(d) Practicality: the cost of the test procedure should be reasonable and customary,

(e) Utility: the usefulness of the procedure is the degree to which it meets the needs of the evaluee, referrer, and payer.

Based on these criteria, existing tests as documented in the Workwell FCE protocol [36] were selected. If unavailable, existing tests documented in other 
literature were selected. Tests were modified from existing tests or test were selfdesigned, when risk factors could not be covered as operational defined.

\section{Results}

Literature review

Nine reviews met the inclusion criteria, four of which were non-systematic and noncritical reviews, two were systematic reviews and four were systematic and critical reviews. A well performed critical review published in a handbook was also included [37]. The results of the literature review are summarized in Table 1.

Risk factors operational definition and selection

\section{Risk factor operational definition:}

There is uniformity between the reviews in the nature of the risk factors and the point of the body being considered. No review reported values of frequency, intensity or total duration. There is consensus about the content of the same risk factors in the three operational definitions (nature, body part considered and exposure). The reviews are uniform in describing the nature of the risk factors, and which body part is being considered. None of the reviews described detailed content of the operational definitions of the risk factors. The nature of the risk factors are operationally defined in the next paragraph.

Nature of the risk factors:

Repetitive movements: repeated or cyclical neck movements, or repeated arm or shoulder motions that generate load to the neck/shoulder region e.g., trapezium muscle [39]. A cycle is a short-term trend that is expected to reverse.

Table 1 Summary of the reviews categorized according to work related physical risk factors in the neck/ shoulder region

\begin{tabular}{llllllllllll}
\hline Risk factor & \multicolumn{1}{l}{ References } \\
\cline { 2 - 11 } & {$[36]$} & {$[37]$} & {$[38]^{* a}$} & {$[38]^{* b}$} & {$[39]$} & {$[40]$} & {$[41]$} & {$[42]$} & {$[43]$} & {$[44]$} \\
\hline Repetitive movements & $\mathrm{C}$ & - & $\mathrm{C}$ & $\mathrm{C}$ & $\mathrm{S}$ & $\mathrm{R}$ & $\mathrm{C}$ & $\mathrm{R}$ & - & - \\
Awkward positions & $\mathrm{C}$ & $\mathrm{S}$ & $\mathrm{C}$ & $\mathrm{C}$ & - & - & $\mathrm{C}$ & $\mathrm{R}$ & $\mathrm{R}$ & $\mathrm{R}$ \\
Forceful movements & - & - & - & $\mathrm{C}$ & $\mathrm{S}$ & - & $\mathrm{C}$ & $\mathrm{R}$ & - & - \\
Static contractions & $\mathrm{C}$ & - & $\mathrm{C}$ & $\mathrm{C}$ & $\mathrm{S}$ & $\mathrm{R}$ & - & - & - & $\mathrm{R}$ \\
\hline
\end{tabular}

$\mathrm{S}$, systematic review; C, systematic and critical review; R, non-systematic and non-critical review; -, no evidence described; ${ }^{* a}$ review dedicated to neck; ${ }^{* b}$ review dedicated to neck/shoulder 
Awkward position: a combination of forceful and repetitive movements in an extreme position of the neck/shoulder region.

Forceful movements: loads to the neck and neck/shoulder, or described exposure as strenuous work involving the upper extremity that generates load to the neck/ shoulder muscles [45].

Static contractions: long-term exposure or static posture that generates load on the neck/shoulder muscles or other prolonged isometric contractions of the neck/ shoulder muscles.

\section{Risk factor selection:}

On the basis of the reviews and the operational process, the following risk factors were included using the inclusion criteria for neck/shoulder region: repetitive movements, awkward position, forceful movements, and static contractions. For each risk factor, operational values are presented in Table 2.

\section{Test design}

An FCE was designed to cover the risk factors for the neck or neck/shoulder region. Tests selected are presented in Table 3. An FCE consisting of seven tests was designed to cover the risk factors. Four functional tests were included from existing tests from the Workwell FCE protocol [36]: repetitive side reaching, static overhead work, front carry and overhead lift. One existing functional test from this FCE was modified: repetitive reaching overhead. One direct performance test described in literature was included: the neck strength test. One functional test was selfdesigned: forward static neck bend test sitting.

The work related risk factors were covered by the tests in Table 3 . The content of these tests is described below. The operational definitions of Table 2 have been used to specify the content of these tests.

\section{Repetitive side reaching test:}

Objective: Fast repetitive movements of the upper extremity. Materials: 30 small objects in bowls, shelf or table of maximal wing span apart, positioned at midthoracic height. Procedure: Sitting with bowls apart at maximal wing span. Remove marbles horizontally at table height from left to right with left arm as fast as possible (and visa versa). Time needed to remove 30 marbles is scored (s). Test-retest reliability: in patient's with chronic low back pain (CLBP), Intraclass Correlation $($ ICC $)=0.45-0.64[58]$; in healthy subjects ICC $=0.74-0.76[59]$ and ICC $=0.54$ 0.72 [60]. The risk factors covered by this test are repetition and awkward positions in the neck and shoulder both in the longitudinal axis.

\section{Repetitive overhead reaching test:}

Objective: Fast repetitive movements of the upper extremity. Materials: 20 marbles and two bowls with a 14-cm diameter positioned at crown height and at table height. 


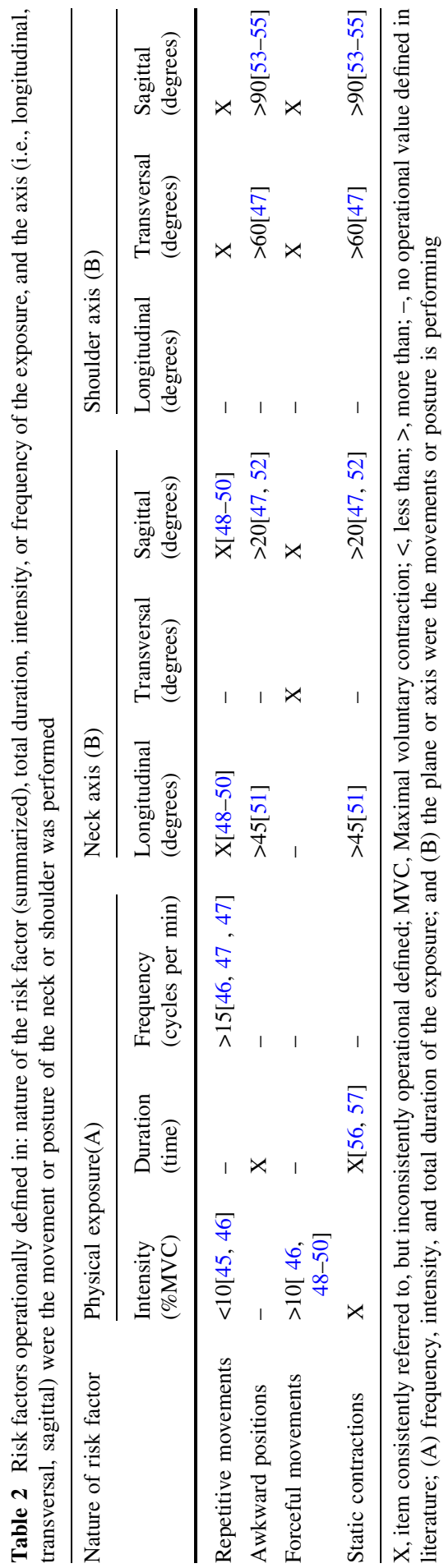


Table 3 Content summary of the FCE based on included risk factors for neck/shoulder region

\begin{tabular}{|c|c|c|c|c|c|c|c|}
\hline \multicolumn{8}{|l|}{ Tests: } \\
\hline Risk factors: & $\begin{array}{l}\text { Repetitive } \\
\text { side } \\
\text { reaching }\end{array}$ & $\begin{array}{l}\text { Repetitive } \\
\text { reaching } \\
\text { overhead }\end{array}$ & $\begin{array}{l}\text { Static } \\
\text { overhead } \\
\text { work }\end{array}$ & $\begin{array}{l}\text { Front } \\
\text { carry }\end{array}$ & $\begin{array}{l}\text { Forward } \\
\text { static bend } \\
\text { neck }\end{array}$ & $\begin{array}{l}\text { Overhead } \\
\text { lift }\end{array}$ & $\begin{array}{l}\text { Neck } \\
\text { strength } \\
\text { test }\end{array}$ \\
\hline $\begin{array}{l}\text { Repetitive } \\
\text { movements }\end{array}$ & $\sqrt{ }$ & $\sqrt{ }$ & - & - & - & - & - \\
\hline $\begin{array}{l}\text { Awkward } \\
\text { positions }\end{array}$ & $\sqrt{ }$ & - & $\sqrt{ }$ & - & $\sqrt{ }$ & - & - \\
\hline $\begin{array}{l}\text { Forceful } \\
\text { movements }\end{array}$ & - & - & - & $\sqrt{ }$ & - & $\sqrt{ }$ & $\sqrt{ }$ \\
\hline $\begin{array}{l}\text { Static } \\
\quad \text { contractions }\end{array}$ & - & - & $\sqrt{ }$ & $\sqrt{ }$ & $\sqrt{ }$ & - & - \\
\hline
\end{tabular}

$\sqrt{ }$-marked cell: coverage of the risk factors by different tests

Procedure: Test adjusted from the IWS FCE dynamic bending. Standing in front of the bowls and moving the marbles as fast as possible from table height to crown height. Test-retest reliability: Test not described in literature. The risk factor covered by this test is repetition in the neck and shoulder in the sagittal axis.

\section{Static overhead work test:}

Objective: Static holding time of shoulder and neck musculature. Materials: Aluminum plate adjustable in height with 20 holes, bolts and nuts and two cuff weights of $1.0 \mathrm{~kg}$ each. Procedure: Standing with hands at crown height, manipulating nuts and bolts wearing cuff weights around the wrists. The time that position is held will be measured in seconds. Test-retest reliability: in healthy subjects ICC $=0.90$ [59]. The risk factors covered by this test are awkward position of the shoulder on the transversal and sagittal axis and static contractions in the neck and shoulder both on the transversal and sagittal axis.

Front carry test:

Objective: Carry weight receptacle in two-handed manner at waist level. Materials: Plastic receptacle $(40 \times 30 \times 26 \mathrm{~cm})$. Weights of 1.0, 2.0, and $4.0 \mathrm{~kg}$. Procedure: Begin with suitable weight, carry $20 \mathrm{~m}$ up and back within 90 s. Increase weights in 4-5 steps until maximum is reached. Test-retest reliability: In CLBP ICC $=0.81$ [61] and 0.87-90 [62]; and in healthy adults ICC $=0.84$ [60]. The risk factors covered by this test are forceful movements and static contractions in the neck and shoulder both around the sagittal, transversal and longitudinal axes. 
Forward static neck bend test sitting:

Objective: Sitting with 20-45 degrees neck flexion and manipulation nut/bolts on table height. Materials: Nut/bolts loaded helmed $(3 \mathrm{~kg}$ ). Procedure: Sitting with 20-45 degrees neck flexion with loaded helmed manipulation nuts/bolts on table height. The time that position is held will be measured in seconds. Test-retest reliability: Test not described in literature. The risk factors covered by this test are awkward positions and static contractions in the neck around the sagittal axis.

\section{Overhead lift test:}

Objective: Functional strength of shoulder and arm musculature. Materials: Plastic receptacle $(40 \times 30 \times 26 \mathrm{~cm})$. A wall mounted system with adjustable shelves and weights of 1.0,2.0, and $4.0 \mathrm{~kg}$. Procedure: Five lifts from waist to crown height and vice versa within $90 \mathrm{~s}$ in standing position. Increase weight in 4-5 steps until maximum is reached. Test-retest reliability: In CLBP ICC $=0.87$ [63] and 0.81-84 [62]; in healthy subjects ICC $=0.89$ [60] and 0.92 [59]. The risk factor covered by this test is forceful movements in the shoulder on the sagittal axis.

Neck strength test:

Objective: Muscular capacity in isometric neck flexion or extension and lateral flexion left and right. Materials: A hand-held dynamometer (type MicroFET2 ${ }^{\circledR}$ ) with a stabilization device and a swivel chair. Procedure: Subject seated on the chair with hands on the hips and feet supported on the floor. The position of the dynamometer is then adjusted to be orthogonal directed against the forehead (in flexion), occipital (in extension) and parietal (lateral flexion) regions. The output was measured by mean of the best 2 of 5 maximal isometric contractions. Testretest reliability: In healthy subjects the reliability is good [64-68]. The risk factor that is covered by this test is forceful movements in the neck on the sagittal and transversal axes.

\section{Discussion}

The objective of this study was to develop an FCE, which is content valid for determining functional capacity in patients with WRND. The importance of this study lies in the fact that previously no such neck-FCE has been described in literature. This neck-FCE is based on the present understanding of physical work related risk factors for the neck. Physical work related factors were identified from epidemiologic review literature for the specific purpose of development of a neckFCE. The literature search resulted in the selection of nine review studies. These WRND studies were the rational basis for a content valid FCE and were used to identify the specific objectives of the instrument [30]. Studies might have been missed because the reviews on risk factors reported on several outcome measures, of which neck pain was one. Keywords indicating the neck were missing and as a 
result studies may have been missed. This was corrected by the overlap of the reviewed studies in the reviews. This means that the same studies were included in different reviews. A substantial overlap between review studies made it necessary to exclude three reviews [69-71].

A disadvantage in the selection of risk factors specifically by use of reviews is that relevant information is lost because of generalization. Checks were necessary to establish whether or not the generalizations in risk factors between the different reviews were defined in the same manner. This was achieved by operationally defining the risk factors into definitions that could be compared. Consensus was reached if the first three operationalised definitions (nature, body part considered and exposure of the risk factor) corresponded. If the operational definitions were not described in the review studies, they were suppleted from other studies. These supplements were drawn from studies that were reviewed by the selected reviews and other WRND studies. This selection was neither systematic nor critical. A weakness in this method is that this supplement is not exhaustive; however it does clarify the boundaries between the risk factors. A strength of this study was that operational risk factors could be easily and objectively modified into test items which covered them. For example, a description of the risk factor 'awkward positions' is not testable until it is operationalised. An important limitation of the literature was the overall absence of definitions of risk factors. There is great uniformity in describing the nature of the risk factors, but only one review described content of the risk factors [42]. It is not certain that reviews dealt with the same content because no definitions were presented. So, there may be overlap or selection bias between the risk factors.

Content validity is that kind of validity which measures the degree to which test items represent the performance domain the test is intended to measure [29]. Content validity is usually determined by a panel of experts or by knowledge of the normal practices that examine the relationship between test objectives and test items $[72,73]$. The FCE in this study is based on the knowledge of present understanding regarding work related risk factors for the neck. Literature research was preferred over an expert panel, to determine risk factors for WRND. This was done because research based information was gathered. This can be considered as a strength of this study. The Dictionary of Occupational Titles (DOT) has been used to assess the content validity of existing FCEs by examining how well the evaluation covers the physical demands defined in the DOT [29, 74]. Even though the DOT taxonomy is widely used, it has not been validated. Post-hoc content analysis of our neck-FCE revealed that the physical demands, lifting, reaching and handling, described in the DOT, are also included in this FCE.

However, the question remains if for the individual WRND-patients with a particular occupation all physical risk factors that might have contributed to its development are covered by the WRND FCE. Furthermore, we do not know if the patient's neck pain is more inconvenient when performing under certain work related activities, or that these work related activities are the primary factors for the development of the WRND. Another important aspect is that patients underestimate their work related functional capacity and therefore possibly have (longer) sick leave. The authors are aware of the fact that psychosocial factors are also of 
importance to sickness absence. Nevertheless, we assume that this neck-FCE is capable to measure the work-related functional capacity of patients with WRND.

WRNDs are usually defined in multidimensional terms [32]. In spite of the relevance of non-physical risk factors, the objective of this study was to use physical risk factors only. For clinical use, it is recommended that the WRND FCE is combined with medical and psychosocial evaluations to assess these other dimensions. Validation of this WRND FCE has started with this study. Further steps in test development will be, determining test-retest reliability and construct and criterion related validity [29], in particular the determination of (reduced) capacity in return to work situations.

\section{Conclusion}

The review has provided evidence that physical risk factors contribute in the development of WRND. These physical risk factors were repetitive movements, forceful movements, awkward positions and static contractions for the neck or neck/ shoulder region. The neck-FCE based on this review provides evidence for the content validity.

Acknowledgement The authors thank M.T. Wolters for critically reviewing prior versions of this manuscript.

\section{References}

1. Ferrari, R., \& Russell, A. (2003). Neck pain. Best Practice \& Research Clinical Rheumatology, 17(1), 57-70.

2. Palmer, K. T., Walker-Bone, K., Griffin, M. J., Sydall, H., Pannett, B., Voggon, D., et al. (2001). Prevalence and occupational associations of neck pain in the Britisch population. Scandinavian Journal of Work, Environment \& Health, 27, 49-56.

3. Houtman, I. L., Goudswaard, A., Dhondt, S., van der Grinten, M., Hildebrandt, V. H., \& van der Poel, E. G. (1998). Dutch monitor on stress and physical load: Risk factors, consequences, and preventive action. Occupational and Environmental Medicine, 55, 73-83.

4. Onishi, N., Namura, H., Sakai, K., Yamamoto, T., Hirayama, K., \& Itani, T. (1976). Shoulder muscle tenderness and physical features of female industrial workers. Journal of Human Ergology, 5(2), 87-102.

5. Bovim, G., Scharder, H., \& Sand, T. (1994). Neck pain in the general population. Spine, 19, 1307-1309.

6. Cote, P., Cassidy, J. D., \& Carroll, L. (1998). The Saskatchewan health and back pain survey. The prevalence of neck pain and related disability in Saskatchewan adults. Spine, 23, 1689-1698.

7. Lau, E. M. C., Sham, A., \& Wong, K. C. (1996). The prevalence and risk factors for neck pain in Hong Kong Chinese. Journal of Public Health Medicine, 18, 396-399.

8. Andersson, H. I., Ejlertsson, G., Leden, I., \& Rosenberg, C. (1993). Chronic pain in a geographically defined general population: Studies of differences in age, gender, social class and pain localization. The Clinical Journal of Pain, 9, 174-182.

9. Schibye, B., Skov, T., Ekner, D., Christiansen, J. U., \& Sjogaard, G. (1995). Musculoskeletal symptoms among sewing machine operators. Scandinavian Journal of Work, Environment \& Health, $21,427-434$.

10. Reneman, M. F., Soer, R., \& Gerrits, E. H. (2005). Basis for an FCE methodology for patients with work-related upper limb disorders. Journal Occupational Rehabilitation, 15(3), 353-363. 
11. Kamwendo, K., Linton, S., \& Mororits, U. (1991). Neck and shoulder disorders in medical secretaries. Scandinavian Journal of Rehabilitation Medicine, 23, 127-133.

12. Sakakibara, H., Miyao, M., Kondo, T., \& Yamada, S. (1995). Overhead work and shoulder-neck pain in orchard farmers harvesting pears and apples. Ergonomics, 38(4), 700-706.

13. Ariens, G. A. M., Borghouts, J. A. J., \& Koes, B. W. (1999). Neck pain. In Crombie I. K. (Ed.). The epidemiology of pain. (pp. 235-255). Seattle: IASP Press.

14. Bongers, P. M., Kremer, A. M., \& ter Laak, J. (2002). Are psychosocial factors, risk factors for symptoms and signs of the shouder, elbow, or hand/wrist? A review of the epidemiological literature. American Journal of Industrial Medicine, 41, 315-342.

15. Loeser, J. D., \& Melzack, R. (1999). Pain: An overview. Lancet, 353, 1607-1609.

16. Soer, R., Gerrits, E. H. J., \& Reneman, M. F. (2006). Test-retest reliability of a WRULD functional capacity evaluation in healthy adults. Work, 26(3), 273-280.

17. Norlander, S., Aste-Norlander, U., Nordgren, B., \& Sahlstedt, B. (1996). Reduced mobility in the cervico-thoracic motion segment: An indicative factor of musculo-skeletal neck-shoulder pain. Scandinavian Journal of Rehabilitation Medicine, 28, 183-192.

18. Norlander, S., Gustravsson, B. A., Lindell, J., \& Nordgren, B. (1997). Reduced mobility in the cervico-thoracic motion segment a risk factor for musculoskeletal neck-shoulder pain: A two-year prospective follow-up study. Scandinavian Journal of Rehabilitation Medicine, 29, 167-174.

19. Borghouts, J. A. J., Koes, B. W., Vondeling, H., \& Bouter, L. M. (1999). Cost-of-illness of neck pain in The Netherlands in 1996. Pain, 80, 629-636.

20. Walker-Bone, K. \& Cooper, C. (2005). Hard work never hurt anyone-or did it? A review of occupational associations with soft tissue musculoskeletal disorders of the neck and upper limb. Annals of the Rheumatic Diseases, 64, 1112-1117.

21. Environmental and health monitoring in occupational health. (1973). Report of a WHO Expert Committee. World Health Organ Tech Rept Ser, 535, 1-48.

22. Abdel-Moty, E., Compton, R., Steele-Rosomoff, R., Rosomoff, L., \& Khalil, T. M. (1996). Process analysis of functional capacity assessment. Journal of Back and Musculoskeletal Rehabilitation, 6, 223-236.

23. Isernhagen, S. J. (1988). Funcional capacity evaluation. In Isernhagen S. J. (Ed.), Work injury management and prevention. (pp. 139-167). Gaithersburg, MD: Aspen Publishers.

24. Isernhagen, S. J. (1992). Return to work testing, functional capacity evaluation and work capacity evaluation. Orthopaedic Physical Therapy Clinics of North America, 1(1), 157-168.

25. Landis, J. R., Roth, D., \& Straaton, K. (1991). Functional capacity evaluation in work disability. Work, 1(3), 37-47.

26. Brouwer, S, Dijkstra, P. U., Steware, R. E., Goeken, L. N. H., Groothoff, J. W., \& Geertzen, J. H. B. (2005). Comparing self-report, clnical examination and functional testing in the assessment of work-related limitations in patients with chronic low back pain. Disability and Rehabilitation, 27(17), 999-1005.

27. Balogh, I., Orbaek, P., Ohlsson, K., Nordander, C., Unge, J., Wsinkel, J., \& Hansson, G. A. (2004). The malmo shouder/neck study group. Applied Ergonomics, 35, 49-56.

28. Hansson, G. A., Balogh, I., Bystrom, J. U., Ohlsson, K., Nordander, C., Asterland, P., Sjolander, S., Rylander, L., Winkel, J., \& Skerfving, S. (2001). Malmo shoulder-neck study group. Questionnaire versus direct technical measurements for assessment of postures and movements of head, upper back, arms and hands. Scandinavian Journal of Work Environment and Health, 27(1), 30-40.

29. Innes, E., \& Straker, L. (1999). Validity of work-related assessments. Work, 13(2), 125-132.

30. Picavet, H. S. J., van Gils, H. W.V., Schouten, J. S. A. G. (2000). Musculoskeletal complaints in the Dutch population: Prevalences, consequences and risk groups (In Dutch: Klachten van het bewegingsapparaat in de Nederlandse bevolking: prevalenties, consequenties en risicogroepen). Bilthoven: Rijksinstituut voor Volksgezondheid en Milieu (RIVM).

31. Reneman, M. F., Dijkstra, P. U., Westmaas, M., \& Goeken, L. N. H. (2002). Test-retest reliabillity of lifting and carrying in a 2-day functional capacity evaluation. Journal of Occupational Rehabilitation, 12(4), 269-275.

32. Feurerstein, M., Shaw, W. S., Nicholas, R. A., \& Huang, G. D. (2004). From confounders to suspected risk factors: Psychosocial factors and work-related upper extremity disorders. Journal of Electromyography and Kinesiology, 14, 171-178.

33. Weevers, H.-J.A., Van der Beek, A. J., Anema, J. R., Van der Wal, G., \& Van Mechelen, W. (2005). Work-related disease in general practice: A systematic review. Family practice, 22, 197-204. 
34. Hagberg, M., Silverstein, B. A., Wells, R. V., et al. (1995). Work related musculoskeletal disorders: A reference for prevention. London: Taylor and Francis 28-137.

35. Hart, D. L., Isernhagen, S. J., \& Metheson, L. N. (1993). Guidelines for functional capacity evaluation of people with medical conditions. JOSPT, 18(6), 682-686.

36. Isernhagen Work Systems (1997). Functional capacity procedure manual 1st edn. Duluth, MN.

37. Nachemson, A., \& Jonsson, E. (2000). Neck and back pain: The scientific evidence of causes, diagnosis, and treatment. Philadelphia, PA: Lippincott Williams and Wilkins.

38. Portney, L. G., \& Watkins, M. P. (1993). Foundations of clinical research: Applications to practice. Norwalk, Connecticut: Appleton \& Lange.

39. Bernard D. P. (Ed). (1997). Musculoskeletal disorders (MSDs) and workplace factors. Cincinnati $(\mathrm{OH})$ : U.S. Department of Health and Human Services.

40. Malchaire, J., Cock, N., \& Vergracht, S. (2001). Review of the factors associated with musculoskeletal problems in epidemiological studies. International Archives of Occupational and Environmental Health, 74(2), 79-90.

41. Winkel, J., \& Mathiassen, S. E. (1994). Assessment of physical work load in epidemiologic studies: Concepts, issues and operational considerations. Ergonomics, 37(6), 979-988.

42. Ariens, G. A., van Mechelen, W., Bongers, P. M., Bouter, L. M., \& van der Wal, G. (2000). Physical risk factors for neck pain. Scandinavian Journal of Work Environment and Health, 26(1), 7-19.

43. Buckle, P. W., \& Devereux, J. J. (2002). The nature of work-related neck and upper limb musculoskeletal disorders. Applied Ergonomics, 33(3), 207-217.

44. Gerr, F., Marcus, M., \& Monteilh, C. (2004). Epidemiology of musculoskeletal disorders among computer users: Lesson learned from the role of posture and keyboard use. Journal of Electromyography and Kinesiology, 14(1), 25-31.

45. Keyserrling, W. M., (2000). Work place risk factors and occupational musculoskeletal disorders, part 2; A review of biomechanical and psychophysical research on risk factors associated with upper extremity disorders. A Journal for the Science of Occupational and Environmental Health and Safety, 61, 231-243.

46. Ohlsson, K., Attewell, R., Skerfving, S. (1989). Self-reported symptoms in the neck and upper limbs of female assembly workers. Scandinavian Journal of Work, Environment \& Health 15(1), 75-80.

47. Jonsson, B. (1988). The static load component in muscle work. European Journal of Applied Physiology, 57, 305-310.

48. Andersen, J. H., Kaergaard, A., Frost, P., Thomsen, J. F., Bonde, J. P., Fallentin, N., Borg, V., \& Mikkelsen, S. (2002). Physical, psychosocial, and individual risk factors for neck/shoulder pain with pressure tenderness in the muscles among workers performing monotonous, repetitive work. Spine, 27(6), 660-667.

49. Kilbom, Å., Horst, D., Kemfert, K., \& Richter, A. (1986). Observation methods for reduction of load and strain on the human body—a review. Abetarskyddsstyrelsen Publikation Service, 171(84), 92.

50. Kilbom, Å., \& Persson, J. (1987). Work technique and its consequences for musculoskeletal disorders. Ergonomics, 30(2), 273-279.

51. Knave, B. G., Wibom, R. I., Voss, M, Hedström, L. D., \& Bergqvist, U. O. (1985). Work with video display terminals among office employees. I. Subjective symptoms and discomfort. Scandinavian Journal of Rehabilitation Medicine, 11(6), 457-466.

52. Ariens, G. A., Bongers, P. M., Hoogendoorn, W. E., van der Wal, G., \& van Mechelen, W. (2002). High physical and psychosocial load at work and sickness absence due to neck pain. Scandinavian Journal of Work Environment and Health, 28(4), 222-231.

53. Ariens, G. A. M., Bongers, P. M., Douwes, M, Miedema, M. C., Hoogendoorn, W. E., van der Wal, G., Bouter, L. M., \& van Mechelen, W. (2001). Are neck flexion, neck rotation, and sitting at work risk factors for neck pain? Results of a prospective cohort study. Occupational and Environmental Medicine, 58(3), 200-207.

54. Rossignol, A. M., Morse, E. P., Summers, V. M., \& Pagnotto, L. D. (1987). Video display terminal use and reported health symptoms among Massachusetts clerical workers. Journal of Occupational Medicine, 29(2), 112-118.

55. Thorn, D. W., \& Deitz, J. C. (1989). Examining content validity through the use of content experts. Occupational Therapy Journal of Research, 9(6), 334-346.

56. Ohlsson, K., Attewell, R., Paisson, B., Karlsson, B., Balogh, I., \& Johnsson, B., et al. (1995). Repetitive industrial work and neck and upper limb disorders in females. American Journal of Industrial Medicine, 27(5), 731-747. 
57. Rosecrance, J. C., Cook, T. M., Wadsroorth, C. T. (1992). Prevalence of musculoskeletal disorders and related job factors in 900 newspaper workers. In Kumar S. (Ed.), Advances in industrial ergonomics and safety. Taylor and Frances.

58. Brouwer, S., Reneman, M. F., Dijkstra, P. U., Groothoff, J. W., Schellekens, J. M. H., \& Goeken, L. N. H. (2003). Test-retest reliability of the Iserhagen work systems functional capacity evaluation in patients with chronic low back pain. Journal of Occupational Rehabilitation, 13(4), 207-218.

59. Skov, T., Borg, V., \& Orhede, E. (1996). Psychosocial and physical risk factors for musculoskeletal disorders of the neck, shoulders, and lower back in salespeople. Journal of Occupational and Environmental Medicine, 53, 351-356.

60. Punnett, L., \& Bergqvist, U. (1997). Visual display unit work and upper extremity musculoskeletal disorders: A review of epidemiological findings. Arbete och Halsa, 16, 1-161.

61. Holmström, E. B., Lindell, J., Moritz, U. (1992). Low back and neck/shoulder pain in construction workers: Occupational work-load and psychosocial risk factors. Spine 17(6), 663-671.

62. Gross, D. P., \& Battie, M. C. (2002). Reliability of safe maximum lifting determinations of a functional capacity evaluation. Physical Therapy, 82(4), 364-371.

63. Reneman, M. F., Brouwer, S., Speelman-Meineman, A., Dijkstra, P. U., Geertzen, J. H. B., \& Groothoff, J. W. (2004). Test-retest reliability of the Isernhagen work systems functional capacity evaluation in healthy adults. Journal of Occupational Rehabilitation, 14(4), 295-305.

64. Agre, J. C., Magness, J. L., Hull, S. Z., Wright, K. C., Baxter, T. L., Patterson, R., \& Stradel, L. (1987). Strength testing with a portable dynamometer: Reliability for upper and lower extremities. Archives of Physical Medicine and Rehabilitation, 86, 454-458.

65. Bohannon, R. W. (1986). Test-retest reliability of hand-held dynamometry during a single session of strength assessment. Physical Therapy, 66(2), 206-209.

66. Bohannon, R. W., \& Andrews, A. W. (1987). Interrater reliability of hand-held dynamometry. Physical Therapy, 67(6), 931-933.

67. Hayes, K. W., \& Falconer, J. (1992). Reliability of hand-held dunamometry and its relationship with manual muscle testing in patients with osteoarthritis in the knee. JOSPT, 16(3), 145-149.

68. Fiebert, I. M., Roach, K. E., Yang, S. S., Dierking, L. D., \& Hart, F. E. (1999). Cervical range of motion and strength during resting and neutral head postures in healthy young adults. Journal of Back and Musculoskeletal Rehabilitation, 12, 165-178.

69. Kuorinka, I., Forcies, L. (Eds). (1995). Work related musculoskeletal disorders (WMSD): A reference book for prevention. London: Taylor \& Francis Ltd, 17-137.

70. Hales, T. R., \& Bernard, B. P. (1996). Epidemiology of work-related musculoskeletal disorders. The Orthopedic Clinics of North America, 27(4), 679-709.

71. Viikari-Juntura, E., Martikainen, R., Luukkonen, R., Mutanen, P., Takala, E. P., \& Riihimaki, H. (2001). Longitudinal study on work related and individual risk factors affecting radiating neck pain. Occupational and Environmental Medicine, 58(5), 345-352.

72. Johnston, M. V., Keith, R. A., \& Hinderer, S. R. (1992). Measurement standards for interdisciplinary medical rehabilitation. Archives of Physical Medicine \& Rehabilitation, 72(12-S), 3-23.

73. Spangfort , E. (1995). Clinical aspects of neck-and shoulder pain. Scandinavian Journal of Rehabilitation Medicine Suppl 32, 43-46.

74. King, P. M., Tuckwell, N., \& Barrett, T. E. (1998). A critical review of functional capactiy functions. Physical Therapy, 78, 852-865. 